\title{
Designing challenging bridges in northwest Spain
}

\author{
F. Nieto, S. Hernández, A. Baldomir \& J. Á. Jurado \\ School of Civil Engineering, University of La Corunna, Spain
}

\begin{abstract}
This work presents two proposals for spanning the Galician rías. The rías are the equivalent to the Scottish firths or the Scandinavian fiords, thus long-span bridges are required to communicate both sides of that physical barrier. Additionally, the multidisciplinary approach applied in the design of these proposals that have been developed in the last decade by the Structural Mechanics Research Group is explained.

Keywords: suspension bridges, sensitivity analysis, optimum design, advanced visualization, aeroelasticity.
\end{abstract}

\section{Introduction}

Galicia is the name of the Spanish region located in the northwestern corner of the Iberian Peninsula (see figure 1). This region does not have high mountains nor large rivers, the main characteristic of the Galician physical geography is the existence of "rias". The rias are sea waters that have advanced deep into the land, in the mouths of some small rivers (see figure 2). Thus, there are two different ways to understand the rias as a frame for the territory: on one hand as sea masses that have penetrated into the land and on the other hand they are also peninsulas that have advanced into the Atlantic ocean. This fact has given birth to a very special and delicate environmental balance that hosts important industries related with the seafood. At the same time, due to their characteristics as natural harbours, they also host crucial industrial and commercial activities and, therefore, the two main metropolitan areas around the cities of La Corunna in the north and Vigo in the south (marked with yellow frames in figure 2) are located around the "Rias Altas" and the "Ría of Vigo", respectively. The existence of the rias has constrained both the road and railway networks in 
Galicia throughout history. To date, the main communication route has followed the north-south orientation along the west coast, but always avoiding spanning the rias. The consequence has been the exclusion of the land peninsulas between the rias from the main communication networks which has been an important drawback in the social and economical development of the Galician west coast.

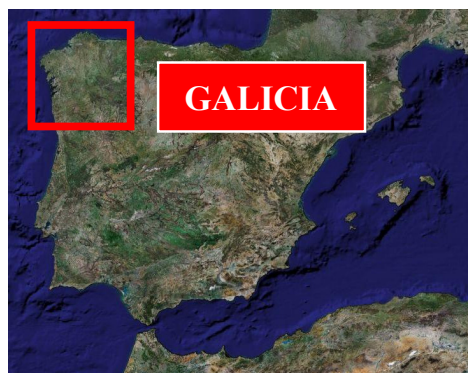

Figure 1: Map of Spain and Galicia location.

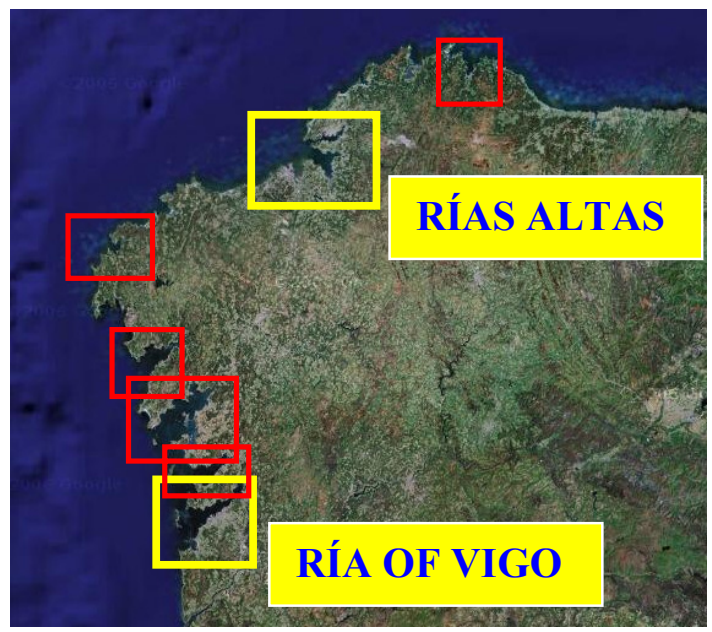

Figure 2: Map of Galicia and location of the main "rías".

However this geographic scenario is not something exclusive of this region. Other very similar landscapes are the Scottish "firths" and the Scandinavian "fiords". It is a wise exercise to analyze how different countries face their geographic constraints and how the provided solutions rely not only on the national economical power, but also on the envision of their engineers and both political and social leaders. Valuable lessons can be learned from the experiences of the United Kingdom and Norway.

Actually, in Scotland three bridges span the natural barrier of the Firth of Forth (figures 3 and 4): the Forth railway Bridge built in 1890, the Kincardine Bridge opened in 1936 and the Forth road bridge inaugurated in 1964. The 
existence of these three bridges built along 75 years is a clue of the importance that some societies give to communication networks. In fact, currently a new road bridge is being constructed parallel to the existing Kincardine Bridge in order to cope with the existing traffic volume [1].

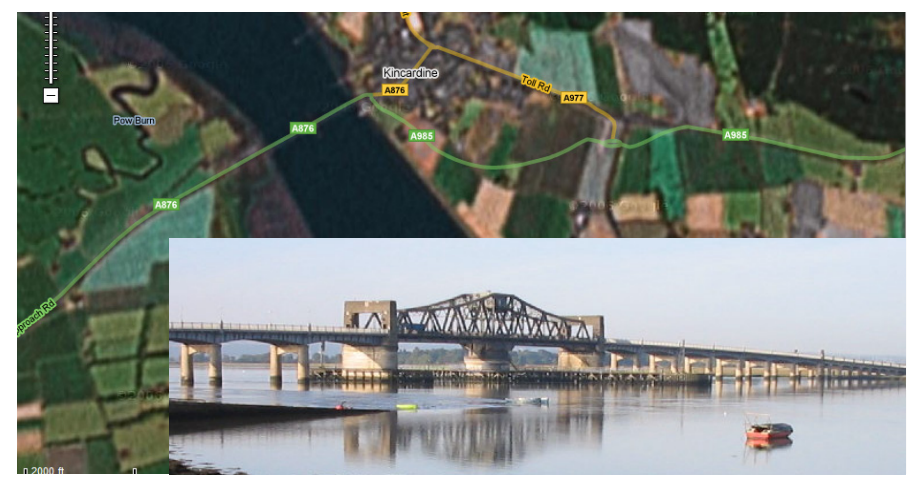

Figure 3: The Kincardine Bridge spanning the Firth of Forth.

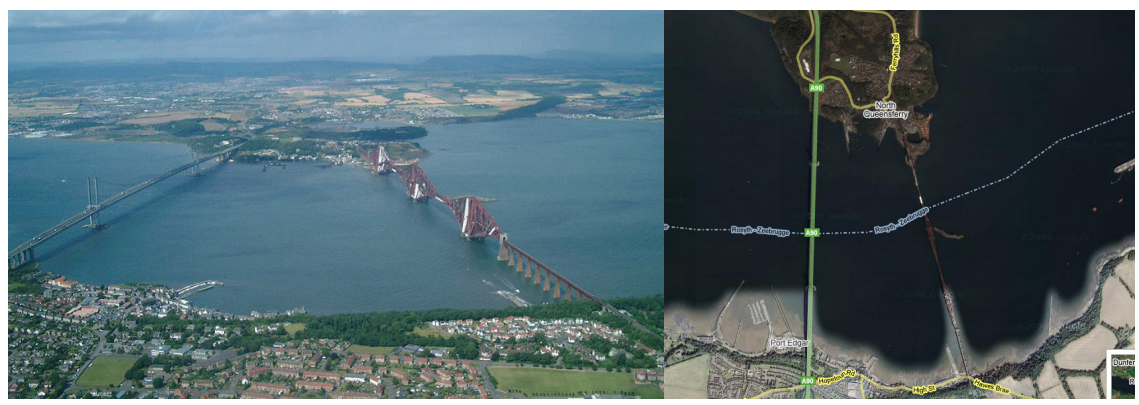

Figure 4: The road and railway bridges over the Firth of Forth.

Another good example of how British people have tackled with transport difficulties is the construction of the Humber Bridge. "For a long time the Humber Estuary was a barrier to trade and development between the two banks and local interests campaigned for over 100 years for the construction of a bridge or tunnel across the estuary" [2]. Finally, the actual bridge was inaugurated in 1981. The opening of the bridge has improved communication enabling the area to realise its potential in commercial, industrial and tourist development. Additionally, it has saved millions of vehicle kilometres as well as drivers and passengers time.

Another good modern example of the aim for overcoming geographic barriers is the Triangle Link [3]. The target of this large and complex project has been to connect two large and several small islands to the main land of Western Norway by means of a 7,9 km tunnel and two suspension bridges: the Storda Bridge with a main span of $677 \mathrm{~m}$ and the Bømla Bridge with a main span of $577 \mathrm{~m}$. 


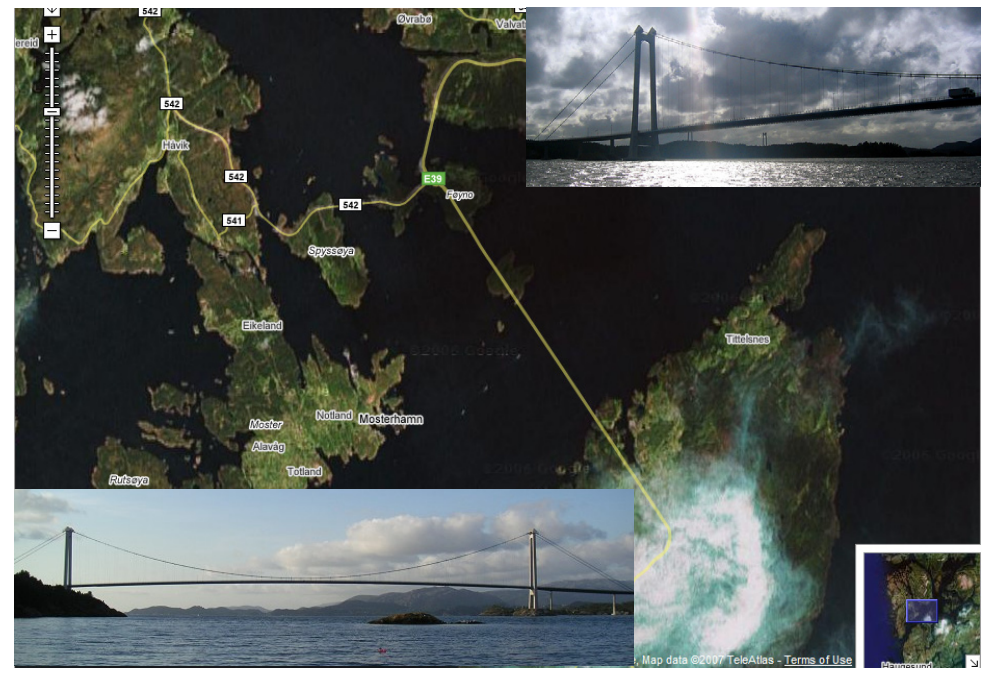

Figure 5: Triangle link location and its two suspension bridges.

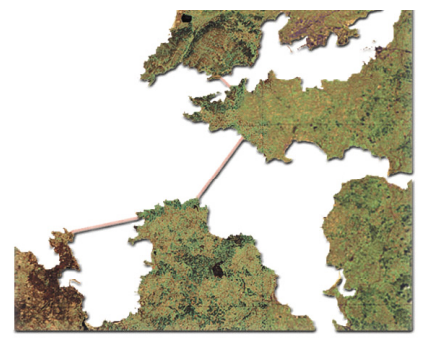

Figure 6: Location of the Rías Altas link.

\section{Spanning the Galician Rías}

On the wake of the existing successful routes all over the world, two challenging links have been proposed by the Structural Mechanics Research Group of the University of La Corunna for the Galician rías: the Rías Altas link in the North and the Balcony Bridge over the Ría of Vigo in the South.

\subsection{The Rías Altas link}

The Rías Altas link [4,5] is a project of a new infrastructure spanning three of the rías located in the North of Galicia. The link will connect the cities of La Corunna and Ferrol which are nowadays joined by a road and a toll highway along distances around $65 \mathrm{Km}$. The Rías Altas link would decrease that distance to $13.9 \mathrm{Km}$. Figure 6 shows a detailed map of the area where the Rias Altas link crossing is projected. Furthermore, in figure 7 the layout of the proposal is presented. It can be seen that two typologies of bridges have been proposed: suspension and arch bridges. 


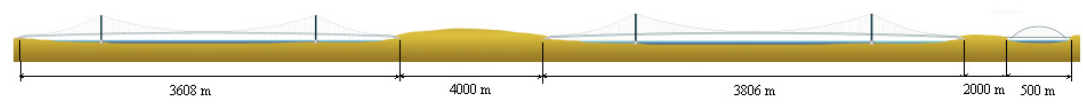

Figure 7: Layout of the Rías Altas link.
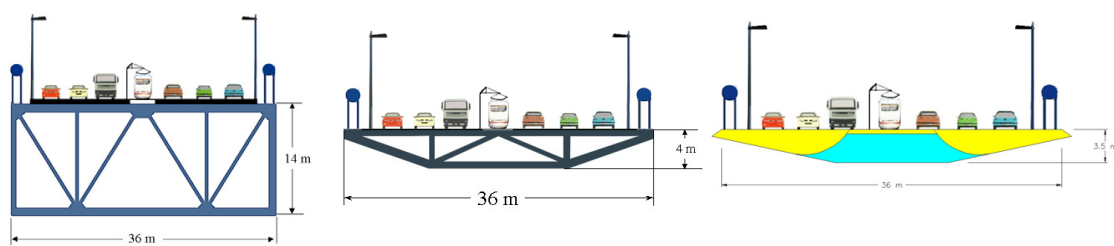

Figure 8: Deck cross-section conceptual design.

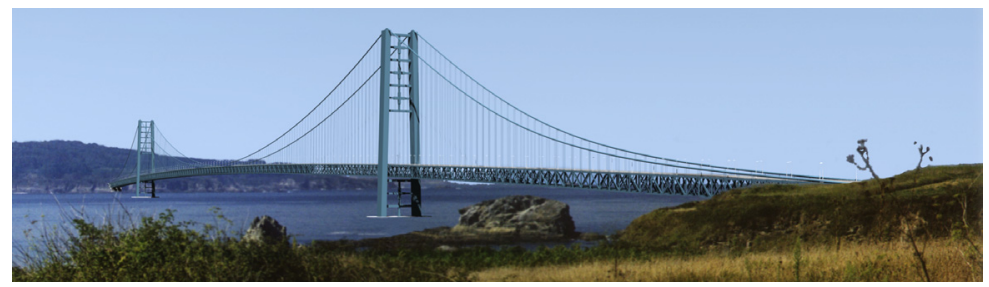

Figure 9: Digital picture of the Ares Bride.

Two suspension bridges have been included in this proposal. They are La Corunna and Ares Bridges. Both have very long main spans: $2016 \mathrm{~m}$ for La Corunna Bridge and $2198 \mathrm{~m}$ for the Ares Bridge. The towers highs are $260 \mathrm{~m}$ for La Corunna Bridge and $296 \mathrm{~m}$ for the Are Bridge.

Regarding the deck cross-section, three different concepts have been considered: a truss girder, a single aerodynamic box and two-box aerodynamic deck with an open grid between the two boxes. The conceptual design of all of them is presented in figure 8. Furthermore, a digital picture of one of the suspension bridges incorporating the existing landscape is shown in figure 9.

The third bridge included in the project is the Ferrol Bridge, corresponding to the northernmost position of the Rías Altas link. This is an arch bridge with a span length of $500 \mathrm{~m}$. The deck is at an intermediate position with respect to the arch and it has an aerodynamic cross-section aiming to favour an efficient behaviour under wind-induced loads. Stiffening elements joining the twin arches of the bridge have the same pattern as the towers of the suspension bridges.

\subsection{The Balcony Bridge over the Ría of Vigo}

This bridge has been projected as a solution for the traffic congestion problem generated as the existing cable-stayed bridge over the Ría of Vigo is not able to cope with the current number of vehicles. The proposed alternative is a new suspension bridge downstream of the existing cable-stayed bridge. 
The projected bridge has a main span of $1800 \mathrm{~m}$ and two secondary spans of $650 \mathrm{~m}$ each. The chosen deck cross-section is a $21.5 \mathrm{~m}$ wide and $4 \mathrm{~m}$ depth symmetric box. Special care has been taken in the aesthetics of the bridge.

One of the key issues of this proposal is the envision of the bridge receiving pedestrians as it will communicate two populated urban areas and the bridge surroundings will attract a number of visitors due to the wonderful existing landscape. In fact, balcony zones have been dedicated around the towers at deck level to allow the recreational use of the structure. In figures 10 and 11 digital visualizations of the Balcony Bridge over the Ría of Vigo are presented.

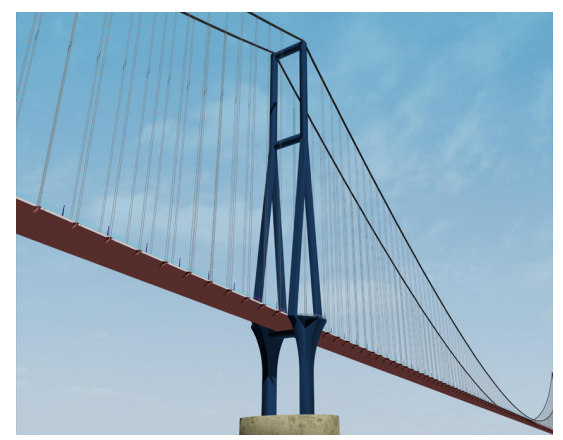

Figure 10: Balcony Bridge visualization.
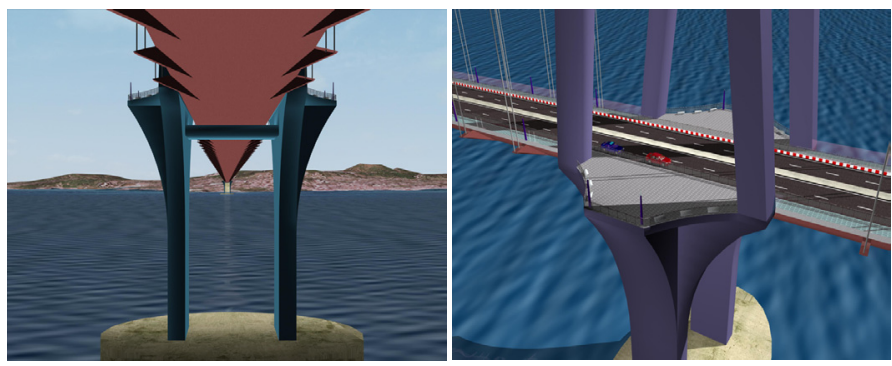

Figure 11: $\quad$ Balcony area around the towers.

\section{Analysis of suspension bridges: a multidisciplinary approach}

The analysis of challenging structures as the ones presented in the former point involves a careful study in order to decide the acting loads and their distribution. In fact, many of the actions to be considered are natural loads in the sense that they are caused by environmental elements. Some of them are listed ahead:

- Wind-induced loads: they are responsible for phenomena such as: static loads acting on the bridge, flutter instability, buffeting, vortex shedding, cable vibrations or pedestrian discomfort amongst others. 
- Earthquake solicitations: they depend on the existing earthquake risk in the bridge location and their expected intensity.

- Sea loads acting on the towers such as waves or the ones cause by tides.

- Thermal loads caused by the environment.

- Snow and ice on the bridge superstructure.

From the aforementioned loads, the ones induced by the wind are the most important in the design of suspension bridges. Moreover, prevention against the destructive aeroelastic phenomenon of flutter must be surveyed in depth as it represents one of the most relevant constraints for the whole design of the bridge.

The Structural Mechanics Research Group has worked extensively for years on defining feasible design strategies of long-span bridges. As a result, a multidisciplinary approach has been proposed and applied to a number of bridges. That methodology comprises aeroelastic studies, sensitivity analyses and optimum design techniques as well as advanced visualization.

\subsection{Aeroelastic studies}

Suspension bridges are wind prone structures. Wind-induced instabilities as flutter can be responsible for the bridge destruction. Thus, special care must be taken to achieve a feasible and safe aerodynamic design. To date, two reliable methods exist in order to analyze the bridge behaviour under wind loads. On one hand, full model testing in boundary layer wind tunnels allows the measurement of model structural responses and the flow speed leading to instabilities such as flutter of buffeting can be observed and evaluated. On the other hand, section model testing of bridge decks in wind tunnels under different flow speeds with the aim of identifying the aerodynamic coefficients and flutter derivatives [6] which are parameters employed in the computer evaluation of the bridge response under wind loads.

\subsection{Sensitivity analysis and optimum design techniques}

The design process of large and complex structures like the proposed suspension bridges for spanning the Galician rías requires a great number of intermediate candidate designs that are evaluated both experimentally and computationally. To date, each design modification is based upon the experience and expertise of the project team, but this circumstance does not guarantee that a modified design is going to perform better that the previous one, which can lead to an inefficient design process.

Alternative approaches are the ones based upon sensitivity analysis and optimum design, that have been extensively used in car or aircraft industries with very good results. Sensitivity analysis can be defined as a response derivative with regards to a design variable, that is, a structural property with a potential for change. This derivative can be understood as the expected change in the studied response when the considered design variable is perturbed. Therefore, the structural behaviour due to a change in a design variable can be anticipated. This 
fact allows the designer to follow a guided design process avoiding unfruitful design modifications. Practical applications of sensitivity analysis in the bridge engineering realm are limited [7-10].

A classical definition for optimum design is the one by Wilde [11]: the best feasible design according to a preselected quantitative measure of effectiveness. In optimal structural design a certain objective function, for instance the structure weight, must be minimized or maximized by modifying the design variables while satisfying a set of behaviour and design constraints. The final optimum design can be accomplished by mathematical methods thanks to the use of computers. Furthermore, when a gradient based method is implemented, evaluation of the sensitivities of the objective function and the constraints is entailed. Several examples of structural optimization can be found in the literature [12-14]. The authors have carried out the optimum design of the record-breaking Messina Strait suspension bridge $[15,16]$.

\subsection{Advanced visualization}

A suspension bridge is a landmark, thus its design involves multiple considerations regarding aesthetics, serviceability, or aeroelastic performance, amongst others. Currently, both a visualization model which represents the appearance of the bridge and a finite element model created to perform the required structural analyses can be worked out. In civil engineering the use of digital models has been mainly devoted to anticipate the visual appearance of the projected structure, but they also are very appropriate for simulate dynamic responses as vibration modes or structural deflections of bridges under windinduced instabilities as flutter. In that respect, many of the experiments carried out in boundary layer wind tunnels can be reproduced by means of computer animations as if it was a virtual wind tunnel. This methodology was first applied to a model of the Tacoma Narrows Bridge which collapsed in 1940 with the aim of simulating its behaviour until reaching the flutter critical wind speed [17].

The methodology carried out to visualize aeroelastic deformation of suspension bridges involves much kind of calculations and a quite large set of different softwares has been used. CIVISM, FLAS and ADISNOL codes have been developed in the University of La Coruña and MAYA [18] is a commercial code. A list of the required task with indication of the associated codes is as follows:

1) A set of data is introduced in the computer and the CIVISM code produces two types of files. One of them will be used as input for the structural model and the second one for the visualization model.

2) A file produced by CIVISM is read by the ADISNOL code and a structural model is created.

3) Calculation of eigenfrequencies and eigenvectors using second order theory is carried out using ADISNOL.

4) With data provided by ADISNOL an aeroelastic analysis of the suspension bridge using modal expansion of the displacements is worked out using the FLAS code. FLAS provides the deformed geometry of bridge for any specified wind speed. 
5) A file produced by CIVISM is read by the visualization software MAYA to produce the visualization model.

6) Using in-house routines and the programming capabilities of MAYA the deformed geometry of the structural model obtained in step 4) is transferred to MAYA and the deformed geometry produced for a wind speed $U$ at any specified time can be visualized.

Producing a large set of simple images, at a ratio of 25 frames per second, a computer animation can be recorded.

In figure 12 a diagram flow explaining the methodology is enclosed.

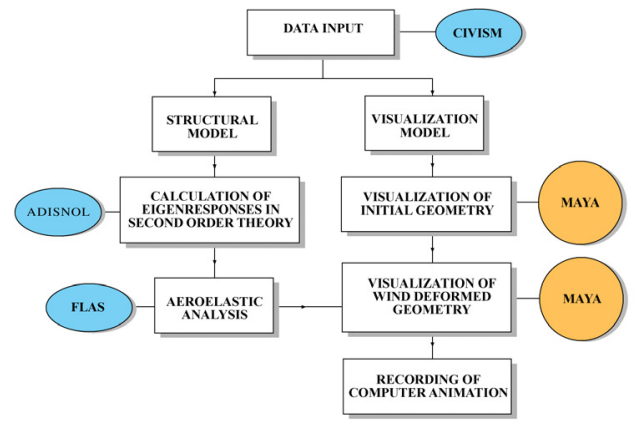

Figure 12: $\quad$ Flow char of the multidisciplinary design approach.

\section{Conclusions}

The Rías Altas link and the Balcony Bridge over the Ría of Vigo can be milestones in the social and economical development of the Spanish Northwestern region.

Multidisciplinary techniques involving advanced visualization, and both sensitivity analysis or optimum design methods can be of great significance in the feasible design of challenging structures in the civil engineering realm.

\section{References}

[1] Upper Forth Crossing at Kincardine http://www.upperforthcrossing.com/ upper_forth/UF_FolderHomePage.jsp?pContentID=25\&p_applic $=$ CCC\& p_service $=$ Content.show \&

[2] Humber Bridge web site http://www.humberbridge.co.uk/explore.php

[3] Schaathun, H. (2001) The triangle link projects, design and construction. Fourth Symposium on Strait Crossings 2001. (Jon Krokeborg Ed.). A.A. Balkena Publishers. Bergen, Norway, 2-5 September.

[4] Hernández S. \& Sánchez A. (2000) Era 2000. Proyecto de enlace en las Rías Altas. University of La Corunna. (In Spanish).

[5] Hernández S. (2001) The Rías Altas link. A challenging crossing. Fourth Symposium on Strait Crossings 2001. (Jon Krokeborg Ed.). A.A. Balkena Publishers. Bergen, Norway, 2-5 September. 
[6] Simiu, E. \& Scanlan, R.H. (1996) Wind Effects on Structures: Fundamentals and Applications to Design. John Wiley \& Sons.

[7] Wang, J., Ko, J. \& Ni, Y. (2000) Modal Sensitivity Analysis of Tsing Ma Bridge for Structural Damage Detection. Nondestructive Evaluation of Highways, Utilities and Pipelines IV.

[8] Jurado J.A. \& Hernández S. (2004) Sensitivity Analysis of Bridge Flutter with respect to Mechanical Parameters of the Deck. Structural and Multidisciplinary Optimization vol. 27(4), pp. 272-283.

[9] Nieto F., Hernández S. \& Jurado J.A. (2005) Distributed Computing for the Evaluation of the Aeroelastic Response and Sensitivity Analysis of Flutter Speed of the Messina Bridge. Fluid Structure Interaction and Moving Boundary Problems, La Corunna, Spain, WIT Press.

[10] Nieto, F. \& Hernández, S. (2006) An Augmented Set of Design Variables for Sensitivity Analysis of Flutter Speed of Cable Supported Bridges. $9^{\circ}$ Convegno Nazionale di Ingegneria del Vento IN-VENTO 2006. Italy.

[11] Wilde, D.J. (1978) Globally Optimal Design. John Wiley \& Sons, NY.

[12] Hernández, S. (1989) Métodos de Diseño Óptimo de Estructuras. Colegio de Ingenieros de Caminos, Canales y Puertos, Madrid. (In Spanish).

[13] Arora, J. (Ed.) (1997) Guide to Structural Optimization. Technical Committee on Optimal Structural Design, ASCE, New York.

[14] Burns, S.A. (Ed.) (2002) Recent Advances in Optimal Structural Design. Technical Committee on Optimal Structural Design, ASCE, Reston.

[15] Nieto, F. (2006) PhD Thesis: Análisis de Sensibilidad y Optimización Aeroelástica de Puentes Colgantes en Entornos de Computación Distribuida. University of La Corunna. (In Spanish).

[16] Nieto, F., Hernández, S. \& Jurado, J.A. (2006) Distributed Computing for Design Optimization of the Messina Bridge considering Aeroelastic Constraints. The Fourth International Symposium on Computer Wind Engineering. Yokohame, Japan. July 16-19, 2006.

[17] Hernández, S., Hernández, L.A. \& Antón, A. (2000) Virtual Laboratories for Analysis and Design of Civil Engineering Structures. Applications of High Performance Computing in Engineering VI. Wit Press.

[18] MAYA (2003) Users Manual, 5.0 version. Alias Wavefront. 